\title{
The outcomes of multivisceral resection for primary T4b colorectal cancer in a tertiary referral centre: a propensity score matching analysis
}

\author{
Marcin Włodarczyk ${ }^{1}$, Kasper Maryńczak를 Przemysław Gajewski ${ }^{1}$, Radzisław Trzciński ${ }^{1}$, \\ Michal Mik르, Adam J. Dziki ${ }^{1}$ Andrew Hill², Łukasz Dziki ${ }^{1}$
}

${ }^{1}$ Medical University of Lodz, Poland
${ }^{2}$ Department of Surgery, Middlemore Hospital, University of Auckland, New Zealand

Submitted: 22 November 2020

Accepted: 26 December 2020

Arch Med Sci

DOI: https://doi.org/10.5114/aoms/131957

Copyright (c) 2021 Termedia \& Banach
Corresponding author:

Łukasz Dziki

Department of General

and Colorectal Surgery

Medical University of Lodz

113 Żeromskiego St

90-549 Lodz, Poland

E-mail:

lukasz.dziki@umed.lodz.pl

\begin{abstract}
Introduction: A multivisceral resection (MVR) is often necessary for patients with colorectal cancer (CRC) because the tumour must be removed en bloc with the infiltrated tissues. The outcomes of MVR are variably presented in the literature. This study aimed to analyse mortality and morbidity of MVR in patients with CRC.

Material and methods: This retrospective study was performed using the Department of General and Colorectal Surgery database of 2204 patients operated on for CRC. Patients with MVR due to stage $\mathrm{pT}$ Th primary CRC were the study group. Patients with no sign of intraoperative infiltration into contiguous structures who had undergone a traditional resection qualified for the control group. Mortality and morbidity for both groups were compared using a propensity score matching analysis.

Results: Patients with no sign of intraoperative infiltration into contiguous structures, who had undergone a traditional resection, qualified for the control group, while 117 patients with MVR due to stage pT4b primary CRC were included in the study group. Early post-operative mortality was not significantly increased in the MVR group ( $3.4 \%$ vs. $1.4 \% ; p=0.284)$. The mean operative time was significantly longer in the MVR group $(p<0.001)$. The 5 -year absolute survival rate was significantly higher in the MVR group (76.7\%) than in the control group $(57.0 \% ; p=0.004)$.

Conclusions: MVR in PT4 CRC is not linked to a higher risk of significant post-operative complications compared to standard resections. Patients with CRC with involvement of contiguous structures, who undergo an MVR, do not appear to have worse long-time outcome than those who do not have involvement of contiguous structures.
\end{abstract}

Key words: T4b colorectal cancer, standard resection, en bloc resection, multivisceral resection.

\section{Introduction}

Colorectal cancer (CRC) is a serious health problem of modern society. In both sexes, it is the second reason for incidence and mortality caused by tumours [1]. A resection with RO margins is considered as a significant prognostic factor associated with lower postoperative complications and higher 5-year survival rates [2, 3]. 
However, $10-20 \%$ of primary and recurrent CRC locally infiltrate contiguous organs. For the best chance of cure the tumour must be removed en bloc with the infiltrated tissues as a multivisceral resection (MVR), but this is thought to be associated with a higher complication rate [4-7].

Because of differing reports in the literature regarding the number of complications after MVR for CRC, this study aimed to investigate outcomes for surgical resection for T3 and PT4b CRC.

\section{Material and methods}

This single-centre, retrospective, propensity score-matched case-control study was conducted in patients operated for primary CRC, who were hospitalized from 2003 to 2019 at the Department of General and Colorectal Surgery at the Medical University of Lodz, Poland.

The study group consisted of patients with stage pT4b primary CRC, who underwent MVR due to infiltration into contiguous organs. Only those patients who had undergone an en bloc resection of contiguous organs were enrolled in this study. The control group were propensity matched, had no sign of intraoperative infiltration into contiguous structures, and underwent a traditional oncological resection of the tumour.

Prior to propensity score matching, baseline patient characteristics were compared by bivariate analyses to assess any imbalance of covariates. Propensity score matching was then applied to minimize the possibility of selection bias and to adjust for significant differences in the baseline characteristics of patients. A multivariate logistic regression analysis was used to obtain propensity scores. The following covariates were included in the regression model: age, sex, BMI index, comorbidities, neoadjuvant treatment, histopathological type of CRC, and primary location of tumour. Covariates with $p<0.05$ were chosen to adjust for significant differences. The next step was the $1: 1$ matching process, using callipers set at 0.2. This propensity score matching was used to evaluate the effect of age itself on both the shortand long-term outcomes. After propensity score matching, baseline characteristics, including covariates not entered into the propensity score model, were compared between groups using bivariate analyses.

The stage of tumour was presented using the TNM scale (American Joint Committee on Cancer). According to the current NCCN guidelines, routine pre-operative work-up was completed for all enrolled CR patients. This included physical examination, total colonoscopy (unless obstructed), abdominal computed tomography (CT), chest X-ray, complete blood count, carcinoembryonic antigen (CEA), and carbohydrate antigen 19-9 (Ca19-9).
Local MVR was defined as en bloc resection of the primary tumour with adjacent involved organs or tissues with tumour invasion confirmed on histopathological examination. An RO resection was defined as a resection with margins free of tumour infiltration in the microscopic examination. The cases in which the margin was infiltrated by the tumour process were referred to as R1 resections, and those patients were excluded from the study.

Patients who had distant metastases were excluded from the study. The exclusions were made before matching the control group. The data for the study was collected using a retrospective analysis of medical documentation, surgical protocols, histopathological findings, and information from the hospital outpatient clinic. Data on long-term outcomes were collected by reviewing patients' records from the hospital outpatient clinic, where the follow-ups were continued. All patients were followed up regularly, at $3,6,9,12,15,18,21$, 24, 30, 36, 42, 48, and 60 months after surgery. Contrast-enhanced CT scan of the abdomen and chest with full colonoscopy were done yearly. Routine blood test and tumour biomarkers were performed at each visit. The data were analysed for age, sex, BMI, clinical symptoms, type of conducted diagnostics, histopathological findings, type of implemented treatment, intra- and post-operative complications, and finally early and long-term treatment results.

\section{Ethical considerations}

The study was conducted in accordance with the ethical principles of the 1975 Declaration of Helsinki, and the study protocol was approved by the Committee of Bioethics of Medical University of Lodz, Poland (RNN/6831/14/KB).

\section{Statistical analysis}

The data gathered in the study were analysed with the statistical package Statistica 13.1 (StatSoft, Inc., USA). The analysed results were presented as mean \pm standard deviation for continuous variables and as numbers and percentage for categorical variables. The $W$ Shapiro-Wilk test was used for estimation of normality of distribution of the examined quantitative parameters. Comparisons of the study groups were performed with Student's t-test or the Mann-Whitney test, depending on the distribution of variables, and the $\chi^{2}$ test (or Fischer test). While comparing more than 2 variables in the normal distribution and equal variances the ANOVA variance analysis was used; otherwise, or in the case of categorical variables, the Kruskal-Wallis test was used. The survival analysis was executed using Kaplan-Meier 
Table I. Detailed demographic data of patients with colorectal cancer qualified for the study

\begin{tabular}{|c|c|c|c|}
\hline Parameter & $\begin{array}{l}\text { Expanded } \\
\text { resections }\end{array}$ & $\begin{array}{l}\text { Control } \\
\text { group }\end{array}$ & $P$-value \\
\hline Age [years] & $64.8 \pm 11.7$ & $63.7 \pm 10.8$ & 0.433 \\
\hline $\operatorname{Sex}(F / M), n$ & $70 / 47$ & $70 / 72$ & 0.869 \\
\hline BMI & $25.3 \pm 3.6$ & $25.7 \pm 3.9$ & 0.396 \\
\hline \multicolumn{4}{|l|}{ T stage, $n$} \\
\hline pT3 & & 142 & $\mathrm{~N} / \mathrm{A}$ \\
\hline pT4 & 117 & & \\
\hline \multicolumn{4}{|l|}{ N stage, $n$} \\
\hline 0 & 42 & 58 & 0.539 \\
\hline 1 & 20 & 27 & \\
\hline 2 & 55 & 57 & \\
\hline \multicolumn{4}{|c|}{ Differentiation degree } \\
\hline $\mathrm{G} 2$ & 79 & 98 & 0.785 \\
\hline G3 & 28 & 36 & \\
\hline G4 & 9 & 8 & \\
\hline
\end{tabular}

statistics, and the statistical significance of the differences between the 2 groups was evaluated with the log-rank test. In all the analyses the probability value $p<0.05$ was considered statistically significant.

\section{Results}

Of all the 2204 CRC patients who had undergone surgery in the Department of General and Colorectal Surgery at the Medical University in Lodz in the years 2003-2016, 117 patients who underwent an en bloc RO MVR of contiguous organs or organ fragments due to tumour infiltration qualified for the study group. There were 142 patients with no intraoperative infiltration into contiguous structures, who underwent a traditional resection due to $C R C$, who were included in the control group. Detailed demographic data of qualified patients are presented in Table I.

The analysed groups were homogeneous in terms of sex, age, and BMI index. In all patients included in the study (Table II), the most frequent location of the cancer was the rectum, which constituted $38.5 \%(n=45)$ of study cases and $39.4 \%$ $(n=56)$ of control cases. All patients with low rectal cancer (located up to $8 \mathrm{~cm}$ from the anal verge) underwent neoadjuvant therapy.

Apart from the intestinal wall invasion of the large bowel, the organ that was most frequently infiltrated and that also required resection along with the primary tumour was the small intestine (Table III, $42.7 \%$ of cases; $n=50$ ).
Table II. Part of the large intestine involved with cancer

\begin{tabular}{|lcc|}
\hline Parameter & $\begin{array}{c}\text { Expanded } \\
\text { resection }\end{array}$ & $\begin{array}{c}\text { Control } \\
\text { group }\end{array}$ \\
\hline Rectum, $n(\%)$ & $45(38.5)$ & $56(39.4)$ \\
\hline Caecum, $n(\%)$ & $26(22.2)$ & $27(19.0)$ \\
\hline Ascending colon, $n(\%)$ & $5(4.2)$ & $5(3.5)$ \\
\hline Hepatic flexure, $n(\%)$ & $3(2.6)$ & $7(4.9)$ \\
\hline Transverse colon, $n(\%)$ & $4(3.4)$ & $6(4.2)$ \\
\hline Splenic flexure, $n(\%)$ & $3(2.6)$ & $1(0.7)$ \\
\hline Descending colon, $n(\%)$ & $3(2.6)$ & $4(2.8)$ \\
\hline Sigmoid colon, $n(\%)$ & $28(23.9)$ & $36(25.4)$ \\
\hline
\end{tabular}

Table III. Additionally, removed organs in multivisceral en block resections of colorectal cancer

\begin{tabular}{|lc|}
\hline Small intestine & 50 \\
\hline Abdominal wall & 35 \\
\hline Bladder & 22 \\
\hline Uterus & 14 \\
\hline Ovary & 6 \\
\hline Spleen & 6 \\
\hline $\begin{array}{l}\text { Vagina } \\
\text { Total* }\end{array}$ & 5 \\
\hline $\begin{array}{l}\text { *Some patients had tumour infiltrating into more than one contiguous } \\
\text { organ. }\end{array}$
\end{tabular}

Early postoperative mortality, defined as death within 30 days of the intervention, was not statistically significant between the 2 groups $(p=0.284)$. The frequency of postoperative complications between the 2 groups was not statistically significant. Complications after interventions in both groups are presented in detail in Table IV.

The mean time of operation was significantly longer in the MVR group than in the control group (178.9 \pm 51.9 min vs. $90.8 \pm 41.1 \mathrm{~min} ; p<0.001$ ). There was a relationship between the number of abdomen organs infiltrated by cancer and the rate of early post-operative complications.

Lymphatic vessel invasion and the lymph node ratio were significantly higher in the MVR group than in the control group (0.88 \pm 1.49 vs. 0.46 $\pm 0.96 ; p=0.006 ; 0.058 \pm 0.101$ vs. $0.030 \pm 0.064$; $p=0.008$, respectively).

For all the patients, the median follow-up time was 41 (2-80) months. The 5-year survival rate was significantly higher in the group of patients who underwent MVR, at $76.7 \%$ compared to $57.0 \%$ in the control group ( $p=0.004$, Figure 2$)$. 
Table IV. Early post-operative complications in the research group of patients who underwent multivisceral en block resections of colorectal cancer and in the control group

\begin{tabular}{|lccc|}
\hline Type of complication & Expanded resection & Control group & $P$-value \\
\hline Death within 30 days, $n$ (\%) & $4(3.4)$ & $2(1.4)$ & 0.284 \\
\hline Haemoperitoneum, $n$ (\%) & $2(1.7)$ & $4(2.8)$ & 0.555 \\
\hline Intestinal?) obstruction, $n(\%)$ & $2(1.7)$ & $6(4.2)$ & 0.244 \\
\hline Wound infection, $n(\%)$ & $10(8.6)$ & $14(9.9)$ & 0.717 \\
\hline Eventration, $n$ (\%) & $3(2.6)$ & $4(2.8)$ & 0.899 \\
\hline Anastomotic leak, $n(\%)$ & $2(1.7)$ & $1(0.7)$ & 0.447 \\
\hline $\begin{array}{l}\text { Coronary artery disease } \\
\text { exacerbation, } n(\%)\end{array}$ & $1(0.8)$ & $3(2.1)$ & 0.414 \\
\hline Pneumonia, $n$ (\%) & $1(0.8)$ & $5(3.5)$ & 0.156 \\
\hline Urinary tract infection, $n(\%)$ & $2(1.7)$ & $7(4.9)$ & 0.159 \\
\hline Total ${ }^{*}, n(\%)$ & $30(25.7)^{*}$ & $46(32.4)^{*}$ & 0.252 \\
\hline
\end{tabular}

${ }^{*}$ Some patients had more than one early post-operative complication.

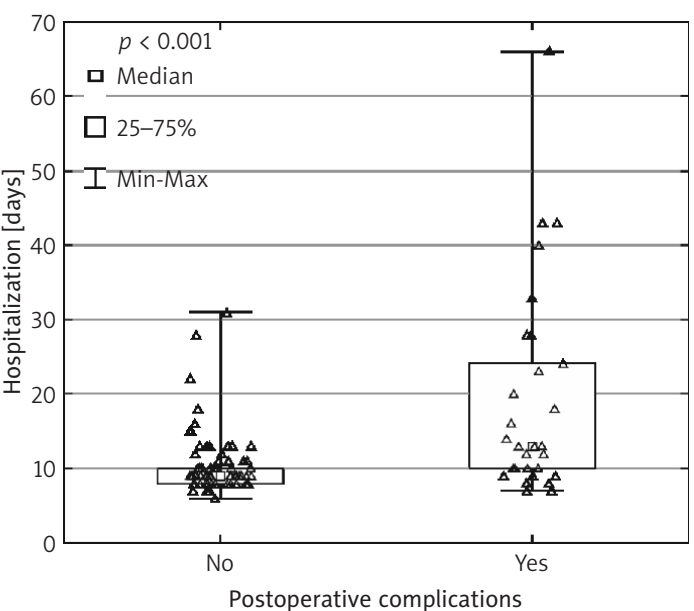

Figure 1. Duration of hospitalization after the intervention of patients who underwent multivisceral en bloc resection of colorectal cancer depending on occurrence of early post-operative complications

\section{Discussion}

In our study, we conducted a retrospective analysis of treatment results in patients who underwent expanded en bloc resections because of locally advanced CRC. Morbidity was similar between patients with involvement of contiguous organs, who underwent MVR, compared to controls, but 5-year survival was higher for MVR patients compared to controls.

In our study, the organ that was most frequently involved with local spread of CRC was the small intestine (47\%). In a large study conducted by Rosander et al. [10] the results were similar. The most frequently infiltrated organ was the small intestine, duodenum, or some other part of the large intestine. In other studies, it has been reported that the vagina and the uterus, or some-

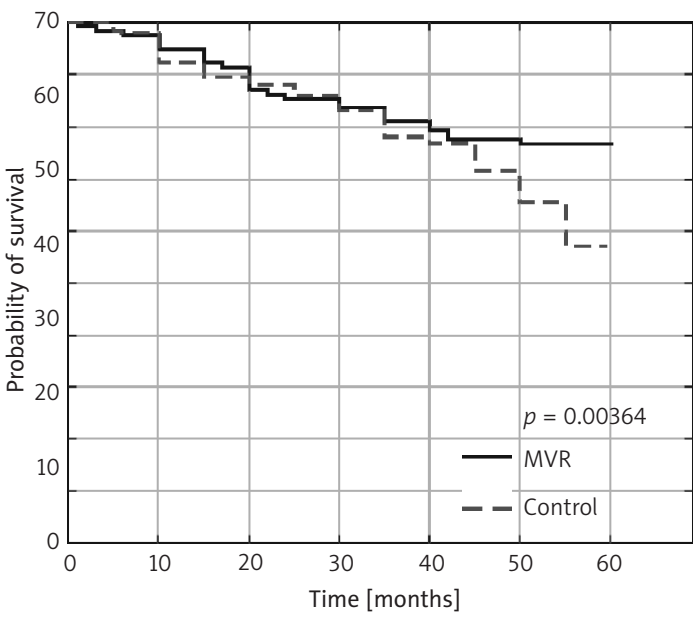

Figure 2. Five-year survival rate of patients who underwent multivisceral en bloc resection and the control group

times the bladder, are the most frequently infiltrated by the tumour $[9,11,12]$.

In our study, we evaluated the frequency of post-operative complications in patients with locally advanced colon cancer, who underwent MVR, compared to controls. In the study, postoperative complications occurred in $23.7 \%$ of patients in the group with expanded resections, and the number was not statistically different from that in the group with elective resections. The total number of complications that were observed was comparable to data presented by others [11-13]. Our observations suggest, however, that in respect of safety, expanded en bloc resections of CRC might be comparable with standard resections if they are executed in centres experienced in this type of intervention. 
Many surgeons believe that the duration of surgery has a significant impact on the patient's recovery [14]. In the current study, the mean operative time was significantly longer in the group of patients who underwent MVR than in the control group, but no impact on the number of early post-operative complications was observed. With the occurrence of complications, the duration of hospitalization was almost doubled. Our observed hospitalization times were comparable with those presented in other studies [15, 16].

In this study the 5-year absolute survival rate in the group of patients who underwent expanded resections was at $76.7 \%$, which was significantly higher compared to elective resections for propensity-matched controls. The five-year survival rate observed in our study is similar to that achieved by other tertiary reference centres for MVR for CRC [17-19]. This emphasizes the importance ofpre-operative evaluation, careful selection of patients, and well-planned expanded resection to achieve optimal results [20-22].

Stage III of the disease, as well as R1 resection, are well-known risk factors for low survival rate and tumour recurrence $[19,20,23,24]$. Tumour infiltration did not turn out to be a prognostic factor in the study lead by Eveno et al. [16], which compared survival rates of patients with T4 tumours to patients with tumours at stages T0-T3. The risk of cancer recurrence in stage III probably does not depend on whether the tumour is locally advanced or not.

Based on conducted analysis, we can establish that multiorgan resections require precise planning of the surgical procedure, and often the intraoperative evaluation during a classical operational technique plays a decisive role. In our opinion, multiorgan resections are advised in locally advanced CRC.

The limitations of this study are inherent to the retrospective design and the tertiary setting of our Department. The latter affects the generalizability of our results because patient and disease characteristics may differ from patients in non-referral centres. Furthermore, it is difficult to determine respectability in hindsight, because this may differ between surgeons and may change over time. Nevertheless, this study presents one of the analyses of outcomes in CRC patients who underwent MVR for true tumour invasion in CRC.

In conclusion, our study confirms that MVR en bloc in PT4 CRC patients is not linked to a higher risk of post-operative complications compared to elective resection of pT3 CRC. Our results emphasize the safety and feasibility of MVR and support the decision to perform extensive surgery in all locally advanced colorectal cancer. However, the choice of patients qualified for a multiorgan resection should be analysed individually by the multidisciplinary team to minimize the risk of post-operative complications and achieve optimal long-term survival.

\section{Acknowledgments}

Marcin Włodarczyk, Kasper Maryńczak and Przemysław Gajewski equally contributed to this paper and thus shared the co-first authorship.

\section{Conflict of interest}

The authors declare no conflict of interest.

\section{References}

1. Siegel R, Naishadham D, Jemal A. Cancer statistics, 2013. CA Cancer J Clin 2013; 63: 11-30.

2. Stintzing S. Management of colorectal cancer. F1000Prime Rep 2014; 6: 108.

3. Khan MA, Hakeem AR, Scott N, Saunders RN. Significance of $\mathrm{R} 1$ resection margin in colon cancer resections in the modern era. Colorectal Dis 2015; 17: 943-53.

4. Smith JD, Nash GM, Weiser MR, Temple LK, Guillem JG, Paty PB. Multivisceral resections for rectal cancer. $\mathrm{Br}$ J Surg 2012; 99: 1137-43.

5. Mohan H, Evans M, Phil M, Larkin J, Beynon J, Winter D. Multivisceral resection in colorectal cancer: a systematic review. Ann Surg Oncol 2013; 20: 2929-36.

6. Lehnert T, Methner M, Pollok A, Schaible A, Hinz U, Herfarth C. Multivisceral resection for locally advanced primary colon and rectal cancer: an analysis of prognostic factors in 201 patients. Ann Surg 2002; 235: 217-25.

7. Rizzuto A, Palaia I, Vescio G, Serra R, Malanga D, Sacco R. Multivisceral resection for occlusive colorectal cancer: is it justified? Int J Surg 2016; 33 Suppl 1: S142-7.

8. Nagasue Y, Akiyoshi T, Ueno M, et al. Laparoscopic versus open multivisceral resection for primary colorectal cancer: comparison of perioperative outcomes. J Gastrointest Surg 2013; 17: 1299-305.

9. Leijssen LGJ, Dinaux AM, Amri R, Kunitake H, Bordeianou LG, Berger DL. The impact of a multivisceral resection and adjuvant therapy in locally advanced colon cancer. J Gastrointest Surg 2019; 23: 357-66.

10. Rosander E, Nordenvall C, Sjövall A, Hjern F, Holm T. Management and outcome after multivisceral resections in patients with locally advanced primary colon cancer. Dis Colon Rectum 2018; 61: 454-60.

11. Gebhardt C, Meyer W, Ruckriegel S, Meier U. Multivisceral resection of advanced colorectal carcinoma. Langenbecks Arch Surg 1999; 384: 194-9.

12. Croner RS, Merkel S, Papadopoulos T, Schellerer V, Hohenberger W, Goehl J. Multivisceral resection for colon carcinoma. Dis Colon Rectum 2009; 52: 1381-6.

13. Gezen C, Kement M, Altuntas YE, et al. Results after multivisceral resections of locally advanced colorectal cancers: an analysis on clinical and pathological t4 tumors. World J Surg Oncol 2012; 10: 39.

14. Duraes LC, Stocchi L, Dietz D, et al. The disproportionate effect of perioperative complications on mortality within 1 year after colorectal cancer resection in octogenarians. Ann Surg Oncol 2016; 23: 4293-301.

15. Larkin J, O'Connell P. Multivisceral resection for T4 or recurrent colorectal cancer. Dig Dis 2012; 30 (Suppl 2): 96-101.

16. Eveno C, Lefevre JH, Svrcek M, et al. Oncologic results after multivisceral resection of clinical T4 tumors. Surgery 2014; 156: 669-75. 
17. Nadiradze G, Yurttas C, Königsrainer A, Horvath P. Significance of multivisceral resections in oncologic surgery: a systematic review of the literature. World J MetaAnal 2019; 7: 269-89.

18. Crawshaw B, Augestad K, Keller D, et al. Multivisceral resection for advanced rectal cancer: outcomes and experience at a single institution. Am J Surg 2015; 209: 526-31.

19. Hallet J, Zih FS, Lemke M, Milot L, Smith AJ, Wong CS. Neo-adjuvant chemoradiotherapy and multivisceral resection to optimize RO resection of locally recurrent adherent colon cancer. Eur J Surg Oncol 2014; 40: 706-12.

20. López-Cano M, Mañas MJ, Hermosilla E, Espín E. Multivisceral resection for colon cancer: analysis of prognostic factors. Dig Surg 2010; 27: 238-45.

21. Mañas MJ, Espín E, López-Cano M, Vallribera F, Armengol-Carrasco M. Multivisceral resection for locally advanced rectal cancer: prognostic factors influencing outcome. Scand I Surg 2015; 104: 154-60.

22. Nahas CSR, Nahas SC, Ribeiro-Junior U, et al. Prognostic factors affecting outcomes in multivisceral en bloc resection for colorectal cancer. Clinics (Sao Paulo) 2017; 72: 258-64.

23. Räsänen M, Ristimäki A, Savolainen R, Renkonen-Sinisalo L, Lepistö A. Oncological results of extended resection for locally advanced rectal cancer: the value of postirradiation MRI in predicting local recurrence. Colorectal Dis 2017; 19: 339-48.

24. Poeze M, Houbiers JG, van de Velde CJ, Wobbes T, von Meyenfeldt MF. Radical resection of locally advanced colorectal cancer. Br J Surg 1995; 82: 1386-90. 